\title{
Effects of implementing a postabortion care strategy in Kinshasa referral hospitals, Democratic Republic of the Congo
}

Daniel Katuashi Ishoso ${ }^{1^{*}} \mathbb{0}$, Antoinette Tshefu' ${ }^{1}$, Thérèse Delvaux ${ }^{2}$, Michèle Dramaix ${ }^{3}$, Guy Mukumpuri ${ }^{4}$ and Yves Coppieters ${ }^{5}$

\begin{abstract}
Objectives: To evaluate the effects of the implementation of a postabortion care (PAC) strategy in Kinshasa referral hospitals, this study analyzed the quality of postabortion care services, including postabortion contraception, and the duration of hospitalization.

Methodology: We estimated the effects of the PAC strategy using a quasi-experimental study by evaluating the outcomes of 334 patients with the diagnosis of a complication of induced abortion admitted to 10 hospitals in which the PAC strategy was implemented compared to the same outcomes in 314 patients with the same diagnosis admitted to 10 control facilities from 01/01/2016 to 12/31/2018. In response to government policy, the PAC strategy included the treatment of abortion complications with recommended uterine evacuation technology, the family planning counseling and service provision, linkages with other reproductive health services, including STI evaluation and HIV counseling and/or referral for testing, and partnerships between providers and communities. The information was collected using a questionnaire and stored using open data kit software. We supplemented this information with data abstracted from patient records, facility registries of gynecological obstetrical emergencies, and family planning registries. We analyzed data and developed regression models using STATA15. Thus, we compared changes in use of specific treatments and duration of hospitalization using a "difference-in-differences" analysis.
\end{abstract}

Results: The implementation of PAC strategy in Kinshasa referral hospitals has resulted in the utilization of WHO recommended uterine evacuation method MVA (29.3\% more in the experimental structures, $p=0.025)$, a non-significant decline in sharp-curettage (19.3\% less, $p=0.132)$, and a decline in the duration of hospitalization of patients admitted for PAC ( 1 day less, $p=0.020$ ). We did not observe any change in the use of PAC services, mortality, and the provision of post abortion contraception.

Conclusion: Despite significant improvement in the management of PAC, the uptake in WHO approved technology — namely MVA, and the duration of hospitalization, these outcomes while a significant improvement for DRC, indicate that additional quality improvement strategies for management of PAC and risk-mitigating strategies to reduce barriers to care are required.

\footnotetext{
*Correspondence: dishosok@gmail.com

${ }^{1}$ Community Health Department, Kinshasa School of Public Health,

University of Kinshasa, PO Box11850, Kinshasa1, Democratic Republic of Congo

This article has been updated to rectify a typo in the abstract and the plain English summary.

Full list of author information is available at the end of the article
} give appropriate credit to the original author(s) and the source, provide a link to the Creative Commons licence, and indicate if changes were made. The images or other third party material in this article are included in the article's Creative Commons licence, unless indicated otherwise in a credit line to the material. If material is not included in the article's Creative Commons licence and your intended use is not permitted by statutory regulation or exceeds the permitted use, you will need to obtain permission directly from the copyright holder. To view a copy of this licence, visit http://creativecommons.org/licenses/by/4.0/. The Creative Commons Public Domain Dedication waiver (http://creativecommons.org/publicdomain/zero/1.0/) applies to the data made available in this article, unless otherwise stated in a credit line to the data. 
Keywords: Democratic Republic of the Congo, Post abortion care, Intervention, Medical practices

\section{Plain English summary}

To evaluate the effects of the implementation of a postabortion care (PAC) strategy in Kinshasa referral hospitals, this study analyzed the quality of postabortion care services, including postabortion contraception, and the duration of hospitalization.

We estimated these effects by evaluating the outcomes of 334 patients with the diagnosis of a complication of induced abortion admitted to 10 hospitals in which the PAC strategy was implemented compared to the same outcomes in 314 patients with the same diagnosis admitted to 10 control facilities from $01 / 01 / 2016$ to $12 / 31 / 2018$. The PAC strategy included the treatment of abortion complications with recommended uterine evacuation technology, the family planning counseling and service provision, linkages with other reproductive health services, including STI evaluation and HIV counseling and/or referral for testing, and partnerships between providers and communities. Patient data were collected from patient records, facility registries of gynecological obstetrical emergencies, and family planning registries, and analysed.

The implementation of PAC strategy in Kinshasa referral hospitals has resulted in the utilization of WHO recommended uterine evacuation method MVA (29.3\% more in the experimental structures, $\mathrm{p}=0.025)$, a non-significant decline in sharp-curettage $(19.3 \%$ less, $\mathrm{p}=0.132$ ), and a decline in the duration of hospitalization of patients admitted for PAC ( 1 day less, $p=0.020$ ). We did not observe any change in the use of PAC services, mortality, and the provision of post abortion contraception.

In conclusion, despite significant improvement in the management of PAC, complications, the uptake in WHO approved technology-namely MVA, and the duration of hospitalization, these outcomes while a significant improvement for DRC, indicate that additional quality improvement strategies for management of PAC and risk-mitigating strategies to reduce barriers to care are required.

\section{Background}

Each year, nearly 73 million abortions are performed worldwide, according to the recent Guttmacher Institute report based on the 2020 Bearak study [1]. Of these abortions, about 25 million are unsafe (performed by persons lacking the necessary skills or in an environment not in conformity with minimal medical standards, or both) and mostly occurred in developing countries, where around
7 million women are hospitalized each year as a result of complications [2,3]. These complications account for about $7.9 \%$ of maternal deaths [4]. Additionally, longterm morbidities occur following unsafe abortions, including subsequent premature births, psychological sequelae, infertility or subfertility, chronic pelvic pain, ectopic pregnancy and spontaneous abortions [5-7].

In the Democratic Republic of Congo (DRC), where legal advances in the practice of abortion are ignored by the population, and by a large majority of healthcare providers who remain committed to article 32 of the code of medical ethics which prohibits this practice unless its indication is the only way to save the life of the mother in danger, the rate of induced abortions is estimated at 55 per 1000 women of childbearing age in Kinshasa its capital [8]. Nearly half of these abortions are followed by complications that include hemorrhage, infection and traumatic injuries (genital trauma and uterine perforation). About $59 \%$ of women with a complication of induced abortion seek care in referral hospitals; the remainder seek care in lower level facilities, health centers and dispensaries [8]. Women admitted to referral hospitals for complications of induced abortions account for about $12.8 \%$ of all gynecological obstetrical emergencies. Mortality among these women was 5.6\%, and half of these deaths occurred after 2 days of hospitalization. These data suggest that some women with complications of induced abortion may be poorly managed [9].

One of the strategic responses to this problem is the implementation of postabortion care (PAC) which consists of emergency treatment for complications related to abortions, family planning counseling and service provision, linkages with other reproductive health services, including STI evaluation and HIV counseling and/ or referral for testing, and partnerships between providers and communities [10]. The DRC Ministry of Public Health through the National Program of Reproductive Health, organized a series of training courses in Obstetric and Neonatal Emergency Care (ONEC) with a focus on PAC. Between February and June 2017, a cascade of trainings in PAC targeted healthcare providers in health facilities in Kinshasa. In this manuscript, we report our evaluation of the effects of these courses on the improvement of quality PAC service provision. Specifically, this study analyzed differences in the following parameters before and after the introduction of PAC: (i) the frequency of patients with a complication of induced abortion admitted for postabortion care; (ii) the frequency of the adequate execution of manual vacuum aspiration 
(MVA and other therapeutic acts; (iii) duration of hospitalization; (iv) deaths related to the complications of induced abortion; and (v) offers of modern postabortion contraceptive methods.

\section{Methods Type of study}

This was a quasi-experimental study of the management of postabortion service delivery before and after the implementation of a PAC strategy in intervention hospitals compared to control hospitals. The period before the intervention was from January 1, 2016 to June 30, 2017, and after was from July 1, 2017 to December 31, 2018.

\section{Setting}

This study was conducted in referral hospitals in Kinshasa. Hospitals are designated as referral hospitals by the DRC Ministry of Health based on the provision of certain services. Referral hospitals support and supervise primary care in health centers, train health professionals, and perform operational and implementation research. They typically have more than 100 inpatient beds which equates to about 100 beds for a population of 100,000 inhabitants [11].

The study population only included women presenting to referral hospitals with complications of induced abortion performed elsewhere.

\section{Package of interventions-implementation of postabortion care (PAC)}

The intervention tested in this study was PAC, which includes the treatment of abortion complications with recommended uterine evacuation technology, the family planning counseling and service provision, linkages with other reproductive health services, including STI evaluation and HIV counseling and/or referral for testing, and partnerships between providers and

Table 1 Summary of the implementation strategy for PAC

\begin{tabular}{|c|c|c|c|c|}
\hline Activities & Main themes & Responsible party & Target & Training materials \\
\hline $\begin{array}{l}\text { Train providers ( } 6 \text { days of } \\
\text { training of trainers followed } \\
\text { by training of providers in } \\
\text { the facilities) }\end{array}$ & $\begin{array}{l}\text { Overview of PAC } \\
\text { Learning objectives: } \\
\text { How to conduct counseling } \\
\text { after an abortion? } \\
\text { How to assess the patient } \\
\text { for complications? } \\
\text { How to treat complications } \\
\text { How to ensure preventive } \\
\text { measures against infections }\end{array}$ & $\mathrm{NPRH}$ & $\begin{array}{l}\text { Providers in health facilities } \\
\text { with obstetric and gyneco- } \\
\text { logic services }\end{array}$ & $\begin{array}{l}\text { Trainer and participant PAC } \\
\text { manual, demonstration tools } \\
\text { (materials and drugs), and } \\
\text { video screenings }\end{array}$ \\
\hline Community sensitization & $\begin{array}{l}\text { Affix PAC wall posters in } \\
\text { health facilities } \\
\text { Provide PAC advice cards at } \\
\text { all health-related activity } \\
\text { (prenatal consultations } \\
\text { days, vaccination, ...) }\end{array}$ & Staff of health facilities & All visitors of health facilities & Wall posters and PAC boards \\
\hline Evaluation of patients & $\begin{array}{l}\text { Inform the patient about her } \\
\text { PAC rights } \\
\text { Perform initial assessment } \\
\text { to identify emergency } \\
\text { conditions } \\
\text { Perform a complete clinical } \\
\text { examination } \\
\text { Request additional examina- } \\
\text { tions }\end{array}$ & Midwives, doctors & $\begin{array}{l}\text { Patients seeking care for } \\
\text { complications of abortions }\end{array}$ & $\begin{array}{l}\text { PAC procedures manual, EONC } \\
\text { wall charts, consultation } \\
\text { form, blood request and } \\
\text { delivery note, transfusion } \\
\text { monitoring sheet, edu- } \\
\text { cational materials (image } \\
\text { boxes, advisory boards and } \\
\text { others), and patient register }\end{array}$ \\
\hline Treatment of patients & $\begin{array}{l}\text { Stabilize the patient's condi- } \\
\text { tion } \\
\text { Deal urgently with the com- } \\
\text { plications of abortions }\end{array}$ & Midwives, doctors & & \\
\hline $\begin{array}{l}\text { Provide postabortion coun- } \\
\text { seling }\end{array}$ & $\begin{array}{l}\text { Explain to the patient how to } \\
\text { take care of her health } \\
\text { Psychologically support the } \\
\text { patient } \\
\text { Provide FP and HIV coun- } \\
\text { seling } \\
\text { Advise during follow-up } \\
\text { consultations }\end{array}$ & Midwives, doctors & & \\
\hline
\end{tabular}


communities. Table 1 presents the activities of the implementation of the PAC intervention, including the main activities, the responsible persons, and the proposed devices.

In December 2016, the National Program for Reproductive Health (NPRH) identified the health facilities eligible for PAC implementation in Kinshasa, including the 29 referral hospitals. In February 2017, an initial 6-day training was organized by the NPRH targeting two providers per eligible hospital. In June 2017, additional training sessions under the supervision of the NPRH were organized in the hospitals that participated in the initial training.

\section{Logic model of the intervention}

Our hypothesis was that if the human, financial, and logistical resources are mobilized for the training of the providers in PAC, the sensitization of the population, and the care of the patients with complication of abortion, then the provider clinical skills will be increased, the population sensitized, and patients admitted for an abortion complication will be properly managed. With these achievements, the outcomes of PAC will be improved, the duration of hospitalization, and maternal deaths due to complications of induced abortion will be reduced.

\section{Criteria for the selection of intervention and control hospitals}

From the original 29 hospitals, ten intervention hospitals were selected because they had completed the entire PAC intervention. This included: (1) declared eligible for PAC implementation by the NPRH in December 2016; (2) represented at the initial training on PAC in February 2017; (3) performed hospital-based training PAC in June 2017 for all providers (midwives and doctors) in the maternity ward. In total, around 100 providers were reached by these trainings in the 10 intervention hospitals.

The intervention hospitals were matched with ten control hospitals. These hospitals were offered the PAC intervention during the study period but did not respond to at least one of the three criterion for the intervention hospitals. Matching was based on type of employer (private, civil state, military state, catholic denominational, protestant denominational, or salvationist denominational) and the type of neighborhood of residence (semirural, eccentric, residential, old cities, and planned cities) [12]. Matching according to the type of employer is taken into account because of the difference that appears in the organization and functioning of the health facilities concerned. The state health facilities have an unlimited range of services, including family planning, they are all over-staffed in the city of Kinshasa, with dilapidated equipment, health care providers with little financial motivation and with several other jobs in order to survive. Faith-based health facilities have a range of services with restrictions in terms of modern contraception for some catholic health facilities, they have understaffed staff compared to the clientele, financially motivated and exhausted each time at the end of service, they are relatively well equipped. Private health facilities, on the other hand, have an unlimited range of services like those in the state, have an adequate number of staff in relation to the clientele, are financially motivated, and are relatively well equipped. And the matching by the type of neighborhood of residence aims at the similarity of the population benefiting from the services.

\section{Data collection}

The impact of implementation of the PAC intervention was estimated by examining the care and outcome of all women who were evaluated at study hospitals for complications of induced abortion. Data were abstracted from all medical records and registers for patients with the diagnosis of complications of induced abortion admitted from January 1, 2016 to December 31, 2018. Data were entered into a digital database installed in the smartphones of nurse and physician investigators. The database included sociodemographic, clinical, paraclinical analysis and therapeutic information, and patient outcomes.

\section{Measurement of the effects of PAC}

We measured the effects of the PAC intervention using variables potentially sensitive to the main activities of the implementation of this intervention (Table 2).

\section{Data analysis}

A comparative description of characteristics was performed at both the individual level (sociodemographic and general clinical characteristics of patients admitted for an induced-abortion related complication) and the structure level to verify the balance between experimental and control structures. At the individual level, a robust standard error linear regression model for cluster sampling was used to compare the mean age of patients in both groups after verification of data normality and homoscedasticity, and logistic regression models with robust standard error for cluster sampling to compare proportions of other categorical variables. At the structure level, the median of percentages by structure accompanied by the minimum and maximum values was used for the "types of provider" and "location of uterine evacuation" variables that were not normally distributed. 
Table 2 Indicators measuring the effects of PAC

\begin{tabular}{|c|c|c|}
\hline $\begin{array}{l}\text { Strategic components of the } \\
\text { PAC }\end{array}$ & Indicators measuring effects & Operational definition \\
\hline \multirow[t]{3}{*}{ Awareness of the population } & $\begin{array}{l}\text { Proportion of patients admitted for induced-abortion } \\
\text { complications }\end{array}$ & $\begin{array}{l}\text { Proportion of patients diagnosed as having induced- } \\
\text { abortion complications among all gynecologic obstet- } \\
\text { ric emergencies }\end{array}$ \\
\hline & Proportion of cases of pelviperitonitis & $\begin{array}{l}\text { Proportion of cases of pelviperitonitis at admission } \\
\text { among all types of induced-abortion complication }\end{array}$ \\
\hline & Proportion of other varieties of abortion complications & $\begin{array}{l}\text { Proportion of cases of hemorrhage, endometritis, pelvic } \\
\text { abscess, and sepsis diagnosed at admission among all } \\
\text { induced-abortion complications }\end{array}$ \\
\hline \multirow[t]{2}{*}{ Acquisition of clinical skills } & Frequency of adequate manual vacuum aspiration & $\begin{array}{l}\text { Frequency of intrauterine manual vacuum aspirations } \\
\text { performed by a trained provider }\end{array}$ \\
\hline & Frequency of dilatation-curettage & Frequency of curettage performed by a trained provider \\
\hline \multirow[t]{2}{*}{$\begin{array}{l}\text { Treatment of complications of } \\
\text { induced abortion }\end{array}$} & Duration of hospitalization & $\begin{array}{l}\text { Number of days between admission and discharge } \\
\text { among survivors }\end{array}$ \\
\hline & Mortality following complications of induced abortion & $\begin{array}{l}\text { Proportion of deaths among patients admitted for an } \\
\text { induced-abortion complication }\end{array}$ \\
\hline Counseling on family planning & $\begin{array}{l}\text { Proportion of patients who received a modern contra- } \\
\text { ceptive method }\end{array}$ & $\begin{array}{l}\text { Proportion of patients who received a modern contra- } \\
\text { ceptive method (contraceptive implant, patch, intrau- } \\
\text { terine device, contraceptive pill,...) after treatment of } \\
\text { the induced-abortion complication }\end{array}$ \\
\hline
\end{tabular}

For analysis of the effects of the intervention, we generated linear regression models with Robust Standard Errors for cluster sampling (ES and p-values adjusted for clustering), and considered an intra-cluster correlation coefficient being different from 0 for all the variables to be significant. The regression models included the period for the "before" and "after" the intervention for each group. We compared changes in use of specific treatments and duration of hospitalization using a "difference-in-differences" analysis. The models included the group, the period, and the interaction between group and period. For the period of hospitalization which was not normally distributed, quantile regression models were used. An $\alpha=0.05$ threshold of significance was chosen.

The data were processed and analyzed using STATA15.

\section{Ethical considerations}

The study was approved by the National Ethics Committee of the Kinshasa School of Public Health (NCE$\mathrm{KSPH}$ ). We obtained consent for data collection from administrators at each health facility. The NCE-KSPH waived the need for consent of the participants because data were drawn from the medical records of patients who had either died or had been discharged from the hospital, and they insisted on the anonymity of patients in the collection and analysis of data. We maintained confidentiality by de-identifying all personal health data. The database was password protected, and access was limited to study personnel.
Table 3 Sociodemographic characteristics of patients

\begin{tabular}{|c|c|c|c|}
\hline Variables & $\begin{array}{l}\text { Intervention } \\
\text { hospitals } \\
(n=334)\end{array}$ & $\begin{array}{l}\text { Control } \\
\text { hospitals } \\
(n=314)\end{array}$ & $\mathrm{p}$ \\
\hline Average age of the patient (SD) & $26.2(7.4)$ & $25.7(6.7)$ & $0.643^{t}$ \\
\hline Adolescent age ( $\leq 19$ years old) & & & 0.891 \\
\hline Yes n (\%) & $71(21.5)$ & $60(20.8)$ & \\
\hline Non (\%) & $260(78.5)$ & $229(79.2)$ & \\
\hline Total n (\%) & $331(100.0)$ & $289(100.0)$ & \\
\hline Marital status & & & 0.281 \\
\hline Single/divorced n (\%) & $91(48.9)$ & $117(57.6)$ & \\
\hline Married/cohabiting n (\%) & $95(51.1)$ & $86(42.4)$ & \\
\hline Total n (\%) & $186(100.0)$ & $203(100.0)$ & \\
\hline Occupational occupation & & & 0.723 \\
\hline Yes n (\%) & $27(32.9)$ & $41(36.0)$ & \\
\hline Non (\%) & $55(67.1)$ & $73(64.0)$ & \\
\hline Total n (\%) & $82(100.0)$ & $114(100.0)$ & \\
\hline Patient parity & & & 0.012 \\
\hline Nulliparous n (\%) & $91(41.9)$ & $83(37.2)$ & \\
\hline Primiparous n (\%) & $43(19.8)$ & $63(28.3)$ & \\
\hline Multiparous n (\%) & $83(38.3)$ & $77(34.5)$ & \\
\hline Total n (\%) & $217(100.0)$ & $223(100.0)$ & \\
\hline
\end{tabular}

With $S D=$ standard deviation; $n=$ number of subjects; $p=p$-value, and ${ }^{t}=t$ test

\section{Results}

Sociodemographic and clinical characteristics of patients During the study period, 334 women were admitted to intervention hospitals and 314 to control hospitals with the diagnosis of a complication of induced abortion. 
Table 4 Clinical characteristics of patients with a complication of induced abortion admitted during the study period for postabortion care

\begin{tabular}{|c|c|c|c|}
\hline Variable & Intervention hospitals $(\mathrm{n}=334)$ & Control hospitals $(n=314)$ & $\mathrm{p}$ \\
\hline \multicolumn{4}{|c|}{ Individual patient level characteristics ${ }^{a}$} \\
\hline Bleeding & & & 0.990 \\
\hline Yes n (\%) & $280(92.7)$ & $264(92.6)$ & \\
\hline No n (\%) & $22(7.3)$ & $21(7.4)$ & \\
\hline Total n (\%) & $302(100.0)$ & $285(100.0)$ & \\
\hline Fever & & & 0.364 \\
\hline Yes n (\%) & $144(59.0)$ & $203(75.7)$ & \\
\hline Non (\%) & $100(41.0)$ & $65(24.3)$ & \\
\hline Total n (\%) & $244(100.0)$ & $268(100.0)$ & \\
\hline Abdominal pain & & & 0.630 \\
\hline Yes n (\%) & $213(83.9)$ & $239(89.5)$ & \\
\hline Non $(\%)$ & $41(16.1)$ & $28(10.5)$ & \\
\hline Total n (\%) & $254(100.0)$ & $267(100.0)$ & \\
\hline Traumatic lesions & & & 0.902 \\
\hline Yes n (\%) & $59(23.4)$ & $56(24.5)$ & \\
\hline Non (\%) & $193(76.6)$ & $173(75.5)$ & \\
\hline Total n (\%) & $252(100.0)$ & $229(100.0)$ & \\
\hline Nauseating debris & & & 0.418 \\
\hline Yes n (\%) & $143(46.6)$ & $163(59.5)$ & \\
\hline No n (\%) & $164(53.4)$ & $111(40.5)$ & \\
\hline Total n (\%) & $307(100.0)$ & $274(100.0)$ & \\
\hline \multicolumn{4}{|c|}{ Hospital level characteristics } \\
\hline \multicolumn{4}{|c|}{ Type of provider } \\
\hline aMidwife & $2.3(0.0-31.3)$ & $14.7(0.0-50.0)$ & \\
\hline${ }^{\mathrm{a} G e n e r a l ~ p r a c t i t i o n e r ~}$ & $85.5(61.9-100.0)$ & $68.1(3.6-100.0)$ & \\
\hline${ }^{a}$ Specialist doctor & $4.5(0.0-22.7)$ & $7.2(0.0-92.9)$ & \\
\hline \multicolumn{4}{|c|}{ Location of uterine evacuation } \\
\hline${ }^{a}$ Emergency room & $2.5(0.0)$ & $3.9(0.0-22.2)$ & \\
\hline aLabor room & $0.0(0.0-61.9)$ & $0(0.0-96.3)$ & \\
\hline aDelivery room & $83.1(0.0-100.0)$ & $89.1(0.0-100.0)$ & \\
\hline aOperating room & $2.5(0.0-100.0)$ & $3.7(0.0-17.9)$ & \\
\hline
\end{tabular}

${ }^{a}$ Numbers indicate median percent (minimum value-maximum value) and $p=p$-value

The sociodemographic characteristics of patients admitted for postabortion care to intervention hospitals compared to control hospitals were not significantly different with exception of parity (Table 3 ).

At the individual level, the clinical characteristics of patients admitted for postabortion care were not significantly different between the intervention and control hospitals. However, at the structural level, there were differences in the type of providers and location of uterine evacuation (Table 4).

\section{Management of postabortion care Number of patients with a complication of induced abortion admitted for postabortion care}

The intervention did not have a significant effect on the number of patients with a complication of induced abortion admitted for postabortion care (Table 5).

\section{PAC management with manual vacuum aspiration}

There was a significant increase in the frequency of manual vacuum aspiration (MVA) in the intervention 
Table 5 Patients with a complication of induced abortion admitted for postabortion care during the period before and after the implementation of the PAC strategy

\begin{tabular}{|c|c|c|c|c|}
\hline Variable & $\begin{array}{l}\text { Before intervention } \\
\mathrm{n}(\%)\end{array}$ & $\begin{array}{l}\text { After intervention } \\
\mathrm{n}(\%)\end{array}$ & Change \% $(95 \% \mathrm{Cl} 95)^{*}$ & $\mathbf{p}^{*}$ \\
\hline \multicolumn{5}{|l|}{ GO emergencies } \\
\hline Intervention hospitals & $1322(10.1 \%)$ & $1470(13.6 \%)$ & $+3.5 \%(-3.4 \mathrm{à}+10.4 \%)$ & $0.284^{t}$ \\
\hline Control hospitals & 1625 (10.9\%) & $1246(11.0 \%)$ & $+0.1 \%(-3.5 \mathrm{à}+3.7 \%)$ & $0.950^{t}$ \\
\hline Difference & & & + 3.4\% (- 3.6 à + 10.4\%) & $0.328^{t}$ \\
\hline \multicolumn{5}{|l|}{ Pelviperitonitis } \\
\hline Intervention hospitals & $120(5.0 \%)$ & $168(2.4 \%)$ & $-2.6 \%(-7.9$ à $+2.7 \%)$ & $0.297^{t}$ \\
\hline Control hospitals & $134(9.7 \%)$ & $125(7.2 \%)$ & $-2.5 \%(-9.8$ à $+4.8 \%)$ & $0.461^{t}$ \\
\hline Difference & & & $-0.1 \%(-8.3 \mathrm{à}+8.1 \%)$ & $0.976^{t}$ \\
\hline \multicolumn{5}{|c|}{ Hemorrhage, sepsis, endometritis, or pelvic abscess } \\
\hline Intervention hospitals & $120(95.0 \%)$ & $168(97.6 \%)$ & $+2.6 \%(-2.7 \grave{a}+7.9 \%)$ & $0.297^{t}$ \\
\hline Control hospitals & $134(90.3 \%)$ & $125(92.8 \%)$ & $+2.5 \%(-4.8$ à $+9.8 \%)$ & $0.461^{t}$ \\
\hline Difference & & & $+0.1 \%(-8.1$ à $+8.3 \%)$ & $0.976^{t}$ \\
\hline
\end{tabular}

With $\mathrm{IC}=$ confidence interval; $\mathrm{n}=$ number of subjects; $\mathrm{p}=\mathrm{p}$-value $;{ }^{\mathrm{t}}=\mathrm{t}$ test; $\mathrm{GO}=$ gynecology and obstetrics; ${ }^{*}=$ clustered robust standard errors (cluster $=$ structure)

Table 6 Treatments received for induced abortion complications

\begin{tabular}{|c|c|c|c|c|}
\hline Variable & $\begin{array}{l}\text { Before intervention } \\
\mathrm{n}(\%)\end{array}$ & $\begin{array}{l}\text { After intervention } \\
\mathrm{n}(\%)\end{array}$ & $\begin{array}{l}\text { Change } \\
\%(\mathrm{Cl} 195 \%)^{*}\end{array}$ & $\mathbf{p}^{*}$ \\
\hline \multicolumn{5}{|l|}{ MVA } \\
\hline Intervention hospitals & $101(24.8 \%)$ & $133(57.1 \%)$ & $+32.4 \%(+7.3 \mathrm{à}+57.5 \%)$ & $0.017^{t}$ \\
\hline Control hospitals & $104(15.4 \%)$ & $103(18.5 \%)$ & +3.1\% (-9.2 à + 15.3) & $0.585^{t}$ \\
\hline Difference & & & $+29.3 \%(+4.2$ à $+54.5 \%)$ & $0.025^{t}$ \\
\hline \multicolumn{5}{|l|}{ Dilatation and curettage } \\
\hline Intervention hospitals & $113(66.4 \%)$ & $150(38.0 \%)$ & $-28.4 \%(-52.0$ à $-4.7 \%)$ & $0.024^{t}$ \\
\hline Control hospitals & $140(64.3 \%)$ & $114(55.3 \%)$ & $-9.0 \%(-24.9 \mathrm{a}+6.9)$ & $0.233^{t}$ \\
\hline Difference & & & $-19.4 \%(-45.1$ à +6.4) & $0.132^{t}$ \\
\hline
\end{tabular}

With $\mathrm{IC}=$ confidence interval; $\mathrm{n}=$ number of subjects; $\mathrm{p}=\mathrm{p}$-value ${ }^{\mathrm{t}}=\mathrm{t}$ test; $\mathrm{MVA}=$ Manual Vacuum Aspiration; ${ }^{*}=$ clustered robust standard errors (cluster $=$ structure)

Table 7 Duration of hospitalization (DH) for treatment of induced abortion complications

\begin{tabular}{|c|c|c|c|c|c|c|}
\hline \multirow[t]{2}{*}{ Variables } & \multicolumn{2}{|c|}{ Before intervention } & \multicolumn{2}{|c|}{ After intervention } & \multirow{2}{*}{$\begin{array}{l}\text { Change } \\
\text { days (CI95\%) }\end{array}$} & \multirow[t]{2}{*}{$\mathrm{p}$} \\
\hline & $\mathrm{n}$ & Med (P25-P75) & $\mathbf{n}$ & Med (P25-P75) & & \\
\hline \multicolumn{7}{|c|}{ DH among survivors (days) } \\
\hline Intervention hospitals & 103 & $3 d(2-4)$ & 153 & $3 d(2-5)$ & $0(-0.8 \mathrm{à}+0.8)$ & $1.000^{k}$ \\
\hline Control hospitals & 110 & $3 d(2-4)$ & 107 & $4 d(2-4)$ & $+1(-0.2 \mathrm{à}+1.8)$ & $0.013^{k}$ \\
\hline Difference & & & & & $-1(-1.8$ à -0.2$)$ & $0.020^{k}$ \\
\hline
\end{tabular}

With $\mathrm{IC}=$ confidence interval; $\mathrm{n}=$ number of subjects; $\mathrm{p}=\mathrm{p}$-value; and $^{\mathrm{k}}=$ quantile regression

hospitals but not in the control hospitals. Conversely, there was a significant decline in dilation and curettage $(D \& C)$ in the intervention hospitals but not in the control hospitals. The difference in changes between the two groups is significant for the MVA $(\mathrm{p}=0.025)$ (Table 6).

\section{Duration of hospitalization among survivors}

The median duration of hospitalization was one longer among survivors in control hospitals during the period after the intervention (4 versus 3 ). The difference in changes between the two groups is significant $(\mathrm{p}=0.020)$ (Table 7). 
Table 8 Deaths due to induced abortion complications, and offer of post abortion contraception

\begin{tabular}{|c|c|c|c|c|}
\hline Variable & $\begin{array}{l}\text { Before intervention } \\
\mathrm{n}(\%)\end{array}$ & $\begin{array}{l}\text { After intervention } \\
\mathrm{n}(\%)\end{array}$ & $\begin{array}{l}\text { Change } \\
\%(\mathrm{Cl} 95 \%)^{*}\end{array}$ & $\mathrm{p}^{*}$ \\
\hline \multicolumn{5}{|l|}{ Lethality } \\
\hline Intervention hospitals & $126(3.9 \%)$ & $183(1.6 \%)$ & $-2.3 \%(-6.4$ à +1.8$)$ & $0.232^{t}$ \\
\hline Control hospitals & $150(3.3 \%)$ & $126(2.4 \%)$ & $-0.9 \%(-4.3 \mathrm{à}+2.4)$ & $0.536^{t}$ \\
\hline Difference & & & $-1.4 \%(-6.2 \grave{a}+3.4)$ & $0.553^{t}$ \\
\hline \multicolumn{5}{|c|}{ Offer of post abortion contraception } \\
\hline Intervention hospitals & $105(34.3 \%)$ & $137(33.6 \%)$ & $-0.7 \%(-18.6 a ̀+17.1)$ & $0.930^{t}$ \\
\hline Control hospitals & $120(25.8 \%)$ & $127(22.0 \%)$ & $-3.8 \%(-13.3$ à + 5.7\%) & $0.391^{t}$ \\
\hline Difference & & & +3.1\% (- 15.1 à + 21.3) & $0.728^{t}$ \\
\hline
\end{tabular}

With $\mathrm{IC}=$ confidence interval; $\mathrm{n}=$ number of subjects; $\mathrm{p}=\mathrm{p}$-value $;{ }^{\mathrm{t}}=\mathrm{t}$ test $;{ }^{*}=$ clustered robust standard errors (cluster $=$ structure)

\section{Deaths due to complications of induced abortion}

The intervention did not have significant effects on deaths related to complications of induced abortion (Table 8).

\section{Provision of postabortion contraception}

The intervention did not have significant effects on the offer of postabortion contraception (Table 8).

\section{Discussion}

The objective of this study was to evaluate the effects of the implementation of a PAC strategy on the management of induced-abortion complications in Kinshasa referral hospitals. This national experience, which includes standard PAC strategies (see Table 1), has the particularity of not including an organizational aspect that has proven successful in several West African countries that have implemented PAC [13]. This includes the creation of areas exclusively dedicated to PAC services, as well as the assignment of trained staff to perform MVAs and provide full-time point-of-treatment counseling and FP services. In addition, aspects of financial subsidy for care and external and internal monitoring were not taken into account in this intervention either.

The quasi-experimental methods used for this purpose, with an ex-post evaluation approach based on the double difference (also known as difference in differences or DID), demonstrated that some PAC treatments improved following the intervention. For example, the frequency of MVA increased and dilation-curettage decreased during the study period in the intervention hospitals but not in the control hospitals. Before the intervention, MVA was performed in less than $25 \%$ of patients in all structures combined; this percentage rose to more than 55 after the intervention in the experimental structures. At the same time, the dilatation-curettage procedure decreased from $65 \%$, on average, in both groups of structures to
$38 \%$ in the experimental structures. This change probably resulted from acquisition of clinical skills by providers. This link between task-transfer training and the execution of therapeutic procedures has been reported for other procedures such as cesarean section and hernia repair $[14,15]$. The increase in MVA may be an important evolution in care. Evacuation of the uterine contents can be life-saving in the presence of an incomplete abortion (spontaneous or induced) since non-evacuation can lead to more serious complications such as haemorrhage, sepsis and death [16, 17]. Evacuation can be performed using either MVA or dilatation-curettage. MVA is now recommended because it is a safer, faster, less painful and less inexpensive method compared to dilation and curettage. In addition, it can be performed by nurses or midwives and without general anesthesia [18-20]. By contrast, dilation-curettage is less frequently recommended because it usually requires general anesthesia, an operating theater and the presence of a general physician or specialist $[18$, 19].

Despite improvements in practice in Kinshasa following implementation of the PAC clinical guidance, optimal practice has not reached the level of some provinces in the east part of the DRC, such as South Kivu and North Kivu, where there was more than 90\% MVA and less than $10 \%$ dilatation-curettage [21]. Similarly, the practice has not reached the level of some other African countries, such as Kenya, with 65\% MVA and 8\% dilation-curettage in 2015 [22], Cameroon, with 73\% MVA and 23\% dilation-curettage in 2014 [23], Egypt, Turkey, Peru, Mexico, Nigeria, Ghana, Senegal, Burkina Faso and Guinea [24-29]. In Ethiopia and Senegal particularly, the level of MVA surpassed the level in DRC in 2004 [30, 31].

However, the change that we observed was greater than that observed in other African countries such as Malawi for example where the percentage of MVA rise from 6.9\% in 2013 to $17.4 \%$ in 2015 with following implementation of a PAC strategy and a corresponding change in 
dilation-curettage use from 91 to $78.9 \%$ during the same period [32]. Modest changes were attributed to defective equipment and a lack of financial support [33]. Similar studies in Zimbabwe and Uganda reported rates of MVA of $12 \%$ and $14 \%$ and rates of dilatation-curettage of $75 \%$ and $69 \%$, respectively $[34,35]$.

These observations suggest a need to further improve implementation of best PAC service delivery practices in Kinshasa.

The intervention appeared to have a significant effect on duration of hospitalization following PAC. Although the duration remained unchanged at 3 days in the intervention hospitals, the duration of hospitalization increased from 3 to 4 days in the control hospitals during the same time period. However, it is not clear that a majority of patients benefited from implementation of the PAC strategy. The range of duration of hospitalization among women treated for induced-abortion complications in the intervention hospitals is essentially the same as observed in Kinshasa hospitals in 2014 (1-3 days) [9], and this duration is higher than in many other African countries, which are below $24 \mathrm{~h}[31,36]$. A possible explanation for prolonged duration of hospitalization in Kinshasa hospitals is that patients are detained for lack of payment of hospitalization costs. It should be noted that in practically the whole city of Kinshasa, hospital costs are borne by patients/families.

Regarding the effects of public awareness activities, the use of PAC services by patients with a complication of induced abortion did not change significantly. However, PAC service use increased numerically in the intervention hospitals, reaching a proportion of $13.6 \%$ among all gynecological obstetrical emergency facilities (3.4\% more than the control hospitals). This trend in intervention hospitals may be the result of the strategy of raising awareness of abortion complications through the use of wall posters and board cards. The level of this indicator remains lower than that of countries such as Nigeria or Somalia [37-39]. There is also a paradox with Nigeria, which has rates of induced abortions and complications that are lower than those in the DRC (33 versus 55 induced abortions per 1000 women of childbearing age and 23 versus 52 complications per 100 induced abortions) $[8,40,41]$ but a higher frequency of complications that present at a hospital. This trend raises suspicion of the existence of abortion complications cases that escape the health system.

Regarding the expected result of emergency treatment of abortion-related complications, the mortality among women with these did not fall significantly during the study period. However, a slight downward trend in mortality was observed in both groups of hospitals. This trend may be related to the effects of other interventions that have been implemented in the context of emergency obstetric and neonatal care. The level of this mortality (1.9\%) remains lower than that of many other countries who have implemented PAC [42-45].

The offer of modern postabortion contraception also did not significantly change with the intervention; paradoxically, a decrease was observed during the same period. In reviewing the family planning records, $21.3 \%$ (74 out of 348) of the patients did not receive modern postabortion contraception. This is mainly a result of the lack of availability of contraceptive supplies and the religious affiliation of some hospitals. This situation contributes to the current problem of the inefficiency and poor uptake of family planning services throughout the country, where the prevalence of modern contraception has remained low at $8 \%$ [46]. The uptake is low despite the strategies to increase utilization, including the purchase of inputs supported by the government, the training of health care providers, mass awareness campaigns and the development of draft legislation to introduce legislation favorable to FP [47]. The level of this indicator in present study was lower than that of the provinces of South Kivu and North Kivu [21].

However, this study had limitation: mortality may be underestimated because the records of these cases were sometimes hidden by persons in charge of the hospitals.

\section{Conclusion}

The implementation of the PAC strategy in Kinshasa referral hospitals improved quality of care for patients admitted for postabortion care. The data indicates the hospital duration was decreased and the uptake of MVA, an approved uterine evacuation technology increased while the utilization of sharp curettage 'an obsolete method' decreased.

However, the use of MVA remains lower than in many other African countries that have implemented this strategy. Given the lack of apparent effect on the use of PAC services by patients (attendance at hospitals offering PAC), the mortality due to complications of induced abortion, and the offer of postabortion contraception, further investigation to determine barriers to quality care and improved outcomes (as for example the negative influences of the absence of areas exclusively devoted to PAC services in hospitals, the absence of financial subsidies and monitoring) is justified. Future strategies to overcome these barriers need to be developed. 


\section{Abbreviations}

DRC: Democratic Republic of the Congo; Cl: Confidence interval; NCE-KSPH: National Ethics Committee of the Kinshasa School of Public Health; MVA: Manual vacuum aspiration; PAC: Post abortion care; n: Number of subjects; SD: Standard deviation; WHO: World Health Organization; p: p-value.

\section{Acknowledgements}

We are very thankful to the team of research nurses and physician for their invaluable contribution for the success of this research study. We are also very grateful to Professor Carl Bose for having willingly accepted to review the manuscript and provide useful inputs.

\section{Authors' contributions}

DIK conceived the study, analyzed data, and drafted manuscript. AT, TD, MD, $\mathrm{GM}$, and YC oriented data analysis and reviewed the manuscript. All authors read and approved the final manuscript.

\section{Funding}

This research was partially funded by an African Doctoral Dissertation Research Fellowship (ADDRF) award offered by the African Population and Health Research Center (APHRC) and in partnership with Ipas, Guttmacher Institute, Gynuity Health Project and Ibis Reproductive Health. The funders had no role in study design, data collection and analysis, decision to publish, or preparation of the manuscript.

\section{Availability of data and materials}

The datasets used and analyzed during the present study are available from the corresponding author upon reasonable request.

\section{Declarations}

\section{Ethics approval and consent to participate}

The study protocol was approved by the institutional review board of the Kinshasa School of Public Health ( $\left.n^{\circ} E S P / C E / 008 / 2019\right)$. This study was conducted in accordance with the Helsinki Declaration II. All administrators of health structures provided written informed consent.

\section{Consent for publication}

Written informed consent was obtained from all health facility administrators for the publication of information drawn from the surveys.

\section{Competing interests}

The authors declare that they have no competing interests.

\section{Author details}

${ }^{1}$ Community Health Department, Kinshasa School of Public Health, University of Kinshasa, PO Box1 1850, Kinshasa1, Democratic Republic of Congo. ${ }^{2}$ Public Health Department, Institute of Tropical Medicine, ITM, Antwerp, Belgium. ${ }^{3}$ Research Centre of Epidemiology, Biostatistics and Clinical Research, School of Public Health, Université Libre de Bruxelles, Brussels, Belgium. ${ }^{4}$ Safe Motherhood Division, National Reproductive Health Program, Ministry of Public Health, Kinshasa, Democratic Republic of Congo. ${ }^{5}$ Research Centre "Policies and Health Systems-International Health", School of Public Health, Université Libre de Bruxelles (ULB), Brussels, Belgium.

Received: 1 April 2020 Accepted: 29 March 2021

Published online: 07 April 2021

\section{References}

1. Bearak J, et al. Unintended pregnancy and abortion by income, region, and the legal status of abortion: estimates from a comprehensive model for 1990-2019. Lancet Glob Health. 2020;8(9):e1152-61.

2. Ganatra B, Gerdts C, Rossier C, Johnson BR Jr, Tuncalp Ö, Assifi A, Sedgh G, Singh S, Bankole A, Popinchalk A, Bearak J, Kang Z, Alkema L. Global, regional, and subregional classification of abortions by safety, 2010-14: estimates from a Bayesian hierarchical model. Lancet. 2017;390:2372-81.

3. Singh S, Maddow-Zimet I. Facility-based treatment for medical complications resulting from unsafe pregnancy termination in the developing world, 2012: a review of evidence from 26 countries. BJOG. 2012. https:// doi.org/10.1111/1471-0528.13552.

4. Say L, Chou D, Gemmill A, Tunçalp Ö, Moller AB, Daniels J, Gülmezoglu AM, Temmerman M, Alkema L. Global causes of maternal death: a WHO systematic analysis. Lancet Glob Health. 2014;2(6):e323-33.

5. Thorp JM, Hartmann KE, Shadigian E. Long-term physical and psychological health consequences of induced abortion: review of the evidence. Obstet Gynecol Surv. 2003;58(1):67-79.

6. Moreau C, Kaminski M, Ancel PY, Bouyer J, Escande B, Thiriez G, Boulot P, Fresson J, Arnaud C, Subtil D, Marpeau L, Rozé JC, Maillard F, Larroque B. Previous induced abortions and the risk of very preterm delivery: results of the EPIPAGE study. EPIPAGE Group. BJOG. 2005;112(4):430-7.

7. De Tourris H, Henrion R, Delecour M. Abrégé de Gymécologie et obstétrique. 6th ed. Paris Milan Barcelone: Masson; 1994. p. 671

8. Ishoso DK, Tshefu AK, Delvaux T, Coppieters Y. Extent of induced abortions and occurrence of complications in Kinshasa, Democratic Republic of the Congo. Reprod Health. 2019;16:49. https://doi.org/10.1186/ s12978-019-0727-4.

9. Ishoso DK, Tshefu AK, Coppieters Y. Analysis of induced abortion-related complications in women admitted to referral health facilities in Kinshasa, Democratic Republic of the Congo. PLoS ONE. 2018;13(8):e0203186. https://doi.org/10.1371/journal.pone.0203186.

10. Groupe de Travail en SAA de I'USAID, Programme ACCESS-PF. Soins après avortement : Manuel de référence. (C) 2010 par la Corporation Jhpiego. Baltimore, Maryland 21231, USA.

11. République Démocratique du Congo, Ministère de la Santé Publique (MSP). Recueil des normes d'organisation et de fonctionnement des structures sanitaires de la zone de sante en République Démocratique du Congo. Secrétariat Général de la Santé, Juillet 2012.

12. Lelo NF, Tshimanga MC. Pauvreté urbaine à Kinshasa. Kinshasa: Edition Cordaid; 2004. p. 41-4.

13. Fariyal F. Fikree, Stembile Mugore, et Heather Forrester, Soins après avortement : Evaluation des services des soins après avortement dans quatre pays de l'Afrique francophone de l'Ouest. Washington, DC: Projet Evidence to Action, Avril; 2014.

14. Bolkan HA, van Duinen A, Waalewijn B, Elhassein M, Kamara TB, Deen GF, et al. Safety, productivity and predicted contribution of a surgical tasksharing programme in Sierra Leone. Br J Surg. 2017;104(10):1315-26.

15. Bhushan H, Bhardwaj A. Task shifting: a key strategy in the multipronged approach to reduce maternal mortality in India. Int J Gynaecol Obstet. 2015;131(Suppl 1):S67-70.

16. Grimes DA, Benson J, Singh S, Romero M, Ganatra B, Okonofua FE, Shas IH. Unsafe abortion: the preventable pandemic. Lancet. 2006;368:1908-19.

17. Ahman $\mathrm{E}$, Shah $\mathrm{H}$. New estimates and trends regarding unsafe abortion mortality. Int J Gynecol Obstet. 2011;115:121-6.

18. Tuncalp O, Gulmezoglu AM, Souza JP. Surgical procedures for evacuating incomplete miscarriage. Cochrane Database Syst Rev. 2010;9:CD001993.

19. World Health Organization. Safe abortion: technical and policy guidance for health systems 2012. http://apps.who.int/iris/bitstream/10665/ 70914/1/9789241548434 eng.pdf. Accessed on 19 Oct 2019.

20. Pereira PP, Oliveira AL, Cabar FR, Armelin AR, Maganha CA, Zugaib M. Comparative study of manual vacuum aspiration and uterine curettage for treatment of abortion. Rev Assoc Med Bras. 2006;52:304-7.

21. Deitch J, Amisi JP, Martinez S, Meyers J, Muselemu JB, Nzau JJ, Wheeler E, Casey SE. "They Love Their Patients": client perceptions of quality of postabortion care in North and South Kivu, the Democratic Republic of the Congo. Glob Health Sci Pract. 2019;7(Suppl 2):S285-98. https://doi. org/10.9745/GHSP-D-18-00368 (Print 2019 Aug 22).

22. Ziraba AK, Izugbara C, Levandowski BA, Gebreselassie H, Mutua M, Mohamed SF, Egesa C, Kimani-Murage EW. Unsafe abortion in Kenya: a cross-sectional study of abortion complication severity and associated factors. BMC Pregnancy Childbirth. 2015;15(15):34. https://doi.org/10. 1186/s12884-015-0459-6.

23. Tumasang F, Leke RJ, Aguh V. Expanding the use of manual vacuum aspiration for incomplete abortion in selected health institutions in Yaoundé, Cameroon. Int J Gynaecol Obstet. 2014;126(Suppl 1):S28-30. https://doi. org/10.1016/j.ijgo.2014.03.014 (Epub 2014 Mar 30).

24. Huntington D. Improving medical care in counselling of post abortion patients in Egypt. Stud Fam Plann. 1995;26:350-62. 
25. Huntington D. The quality of abortion services in Turkey. Int J Gynecol Obstet. 1996;53:41-4.

26. Huntington D, Askew I, Khan ME, et al. Recherches opérationnelles sur les Soins Après Avortement. New-York: Population Council Inc; 1998. p. 35.

27. Advance Africa. Soins Après Avortement: un compendium de pratiques. Advance Africa. 2002; 44 p.

28. Ministère de la santé du Burkina Faso. Introduction du traitement médical d'urgence ainsi que les services et conseils en planification familiale pour les femmes qui souffrent de complications suite à un avortement. Ouagadougou: Population Council/CRESAR; 1998. p. 34.

29. Centre de formation et de recherche en santé de la reproduction (CEFOREP). Introduction des soins obstétricaux d'urgence et de la planification familiale pour les patientes présentant des complications liées à un avortement incomplet. Dakar: CEFOREP; 1998. p. 30.

30. Fetters T, Tesfaye $S$, Clark KA. An assessment of postabortion care in three regions in Ethiopia, 2000 to 2004. Int J Gynaecol Obstet. 2008;101(1):1006. https://doi.org/10.1016/j.ijgo.2008.01.011 (Epub 2008 Mar 4).

31. Cheikh TC, Abdoulaye D, El Hadj OF. Amélioration de la qualité des soins après avortement (SAA) en zone rurale au Sénégal. Cahiers Santé. 2004:14:245-50.

32. Maria LO, Gladys MG, Ursula K, Geir W, James K, Elisabeth D. The use of manual vacuum aspiration in the treatment of incomplete abortions: a descriptive study from three public hospitals in Malawi. Int J Environ Res Public Health. 2018;15:370. https://doi.org/10.3390/ijerph15020370.

33. Maria LO, Gladys MG, Ursula K, Geir W, James K, Elisabeth D. "Confidence comes with frequent practice": health professionals' perceptions of using manual vacuum aspiration after a training program. Reprod Health. 2019;16:20. https://doi.org/10.1186/s12978-019-0683-z.

34. Madziyire MG, Polis CB, Riley T, Sully EA, Owolabi O, Chipato T. Severity and management of postabortion complications among women in Zimbabwe, 2016: a cross-sectional study. BMJ Open. 2018;8(2):e019658. https://doi.org/10.1136/bmjopen-2017-019658.

35. Mellerup N, Sørensen BL, Kuriigamba GK, Rudnicki M. Management of abortion complications at a rural hospital in Uganda: a quality assessment by a partially completed criterion-based audit. BMC Womens Health. 2015;20(15):76. https://doi.org/10.1186/s12905-015-0233-y.

36. Abdhalah KZ, Chimaraoke I, Brooke A, Hailemichael G, Michael M, Shukri F, Caroline E, Elizabeth W. Unsafe abortion in Kenya: a cross-sectional study of abortion complication severity and associated factors. BMC Pregnancy Childbirth. 2015;15:34. https://doi.org/10.1186/s12884-015-0459-6.

37. Ekanem El, Etuk SJ, Ekabua JE, Iklaki C. Clinical presentation and complications in patients with unsafe abortions in University of Calabar Teaching Hospital, Calabar, Nigeria. Niger J Med. 2009;18(4):370-4.
38. Ibrahim IA, Onwudiegwu U. Sociodemographic determinants of complicated unsafe abortions in a semi-urban Nigerian town: a four-year review. West Indian Med J. 2012;61(2):163-7.

39. Chukwumalu K, Gallagher MC, Baunach S, Cannon A. Uptake of postabortion care services and acceptance of postabortion contraception in Puntland, Somalia. Reprod Health Matters. 2017;25(51):48-57. https://doi. org/10.1080/09688080.2017.1402670 (Epub 2017 Dec 12).

40. Bankole A, Adewole IF, Hussain R, Awolude O, Singh S, Akinyemi JO. The incidence of abortion in Nigeria. Int Perspect Sex Reprod Health. 2015;41(4):170-81. https://doi.org/10.1363/4117015.

41. Sudhinaraset M. Reducing unsafe abortion in Nigeria. Issues Brief (Alan Guttmacher Inst). 2008;3:1-3.

42. Gebreselassie H, Fetters T, Singh S, Abdella A, Gebrehiwot Y, Tesfaye S, Geressu T, Kumbi S. Caring for women with abortion complications in Ethiopia: national estimates and future implications. Int Perspect Sex Reprod Health. 2010;36(1):6-15.

43. Owolabi OO, Cresswell JA, Vwalika B, Osrin D, Filippi V. Incidence of abortion-related near-miss complications in Zambia: cross-sectional study in Central, Copperbelt and Lusaka Provinces. Contraception. 2017;95(2):167-74. https://doi.org/10.1016/j.contraception.2016.08.014 (Epub 2016 Sep 1).

44. Melese T, Habte D, Tsima BM, Mogobe KD, Chabaesele K, Rankgoane G, Keakabetse TR, Masweu M, Mokotedi M, Motana M, Moreri-Ntshabele B. High levels of post-abortion complication in a setting where abortion service is not legalized. PLoS ONE. 2017;12(1):e0166287. https://doi.org/ 10.1371/journal.pone.0166287.

45. Kalilani-Phiri L, Gebreselassie H, Levandowski BA, Kuchingale E, Kachale F, Kangaude G. The severity of abortion complications in Malawi. Int J Gynaecol Obstet. 2015;128(2):160-4. https://doi.org/10.1016/j.ijgo.2014 08.022 (Epub 2014 Nov 6)

46. Ministère du Plan et Suivi de la Mise en œuvre de la Révolution de la Modernité (MPSMRM), Ministère de la Santé Publique (MSP), ICF International. Enquête démographique et de santé en République Démocratique du Congo 2013-2014. Rockville: MPSMRM, MSP, and ICF International; 2014.

47. Ministère de la Santé Publique (MSP) de la République Démocratique du Congo (RDC). Planification Familiale: Plan stratégique national à vision multisectorielle (2014-2020). Kinshasa: MSP, Secrétariat Général de la Santé; 2014.

\section{Publisher's Note}

Springer Nature remains neutral with regard to jurisdictional claims in published maps and institutional affiliations.
Ready to submit your research? Choose BMC and benefit from:

- fast, convenient online submission

- thorough peer review by experienced researchers in your field

- rapid publication on acceptance

- support for research data, including large and complex data types

- gold Open Access which fosters wider collaboration and increased citations

- maximum visibility for your research: over $100 \mathrm{M}$ website views per year

At BMC, research is always in progress.

Learn more biomedcentral.com/submissions 